\title{
Effects of Diethyltindichloride on Amino Acid and Nucleoside Transport in Suspended Rat Thymocytes ${ }^{1,2}$
}

\author{
Roland R. Miller, ${ }^{3}$ Rolf Hartung, And H. H. Cornish \\ Interdepartmental Program in Toxicology and Department of Environmental and Industrial Health, \\ University of Michigan, Ann Arbor, Michigan 48109
}

Received April 10, 1980; accepted July 7, 1980

\begin{abstract}
Effects of Diethyltindichloride on Amino Acid and Nucleoside Transport in Suspended Rat Thymocytes. Miller, R. R., HaRTUng, R., ANd CoRnish, H. H. (1980). Toxicol. Appl. Pharmacol. 55, 564-571. The effects of diethyltindichloride (DETD) on basic biochemical processes of thymus cells were investigated in order to develop an understanding of the mechanism by which dialkyltins act on the thymus of rodents in vivo. Accumulation of the nonmetabolizable amino acid $\alpha$-aminoisobutyrate (AIB) was markedly inhibited by the dialkyltins in suspended rat thymocytes. The inhibitory effects on AIB influx were apparent after as little as 5 min of thymocyte preincubation with DETD. Low dialkyltin concentrations, which did not inhibit AIB influx in noninsulin-stimulated cells, abolished the insulin-mediated AIB influx. Addition of lipoic acid (reduced) to the incubation medium prevented the inhibitory action of DETD on AIB influx. DETD markedly inhibited labeled thymidine incorporation into DNA of suspended rat thymocytes, possibly via inhibition of transmembrane transport of this nucleoside precursor. In sharp contrast to its effect on thymidine incorporation, DETD stimulated the incorporation of labeled uridine into RNA.
\end{abstract}

Di- $n$-octyltindichloride has been shown to selectively affect the thymus gland and thymus-dependent lymphoid tissue of rats (Seinen and Willems, 1976). Di- $n$-octyltindichloride (DOTC) and di- $n$-butyltindichloride (DBTC) were the most potent in a series of dialkyltin compounds given in the diet; thymic atrophy also occurred to a lesser extent in rats given di- $n$-propyltindichloride (DPTC) and diethyltindichloride (DETD). Lymphoid atrophy did not occur in mice, guinea pigs, or Japanese quail fed DBTC or DOTC, indicating a species difference in

\footnotetext{
${ }^{1}$ Presented in part at the $17 \mathrm{th}$ annual meeting of the Society of Toxicology, San Francisco, California, 1978.

${ }^{2}$ The data reported represent a portion of the work submitted by Roland R. Miller in partial fulfillment of the requirement for Doctor of Philosophy in Toxicology at the University of Michigan.

${ }^{3}$ Present address: Toxicology Research Laboratory, 1803 Building, Dow Chemical U.S.A., Midland, MI 48640 .
}

susceptibility to the dialkyltins (Seinen et al., 1977b). Suppression of thymus-dependent immunity was demonstrated in DOTC- and DBTC-treated rats (Seinen et al., 1977a).

The dialkyltin-induced thymic atrophy was characterized by a relative depletion of thymic cortical lymphocytes. Histological signs of thymic cell destruction, as seen after treatment with corticosteroids, were not observed in dialkyltin-treated animals and thymus weights were found to be as severely depressed in adrenalectomized animals as in intact animals given DOTC. For these reasons the thymic atrophy and depletion of thymic cortical lymphocytes were not considered to be stress related. In vitro studies with rat thymocyte cultures indicated that DOTC and DBTC decreased cell counts and cell viability at concentrations of 0.012 and $0.120 \mu \mathrm{M}$ during a 24-hr incubation in- 
terval. DETD had no distinct effect in viability of rat thymocytes in vitro at concentrations of 0.012 and $0.120 \mu \mathrm{M}$, consistent with the lesser potency of DETD in vivo. Bone marrow cell number and viability were not affected when incubated with $50 \mu \mathrm{g} / \mathrm{ml}$ of DOTC or DBTC for $40 \mathrm{hr}$. Survival of human thymocytes was markedly decreased by DBTC in vitro, suggesting that the dialkyltins act in the same manner in humans and rats.

The present in vitro investigation of the effects of DETD on some basic biochemical processes of rat thymus cells was conducted in order to develop a more complete understanding of the mechanism(s) by which dialkyltins act on the thymus in vivo.

\section{METHODS}

Suspension of rat thymocytes. Thymus glands were removed from 4- to 8-week-old male and female Wistar rats, and teased apart with scissors and forceps in $25 \mathrm{ml}$ of buffered glucose salt medium (GS medium) containing $120 \mathrm{mM} \mathrm{NaCl}, 5 \mathrm{mM} \mathrm{KCl}, 1 \mathrm{mM} \mathrm{CaCl}{ }_{2}, 2.5 \mathrm{mM}$ $\mathrm{MgCl}_{2}, 1.5 \mathrm{mM} \mathrm{NaH}_{2} \mathrm{PO}_{4}, 22 \mathrm{~mm}$ glucose. $25 \mathrm{~mm}$ Tris (hydroxymethyl aminomethane), and $20 \mathrm{mM} \mathrm{N}$-2-hydroxyethylpiperazine- $N^{\prime}$-2-ethanesulfonic acid (Hepes), pH 7.5. This GS medium has been used by other investigators for studies involving amino acid transport in suspended rat thymocytes (Goldfine et al., 1975, 1972). After teasing glands apart, the cells were filtered through gauze and centrifuged at $500 \mathrm{~g}$ for $5 \min \left(23^{\circ} \mathrm{C}\right)$. The supernatant was discarded and cells were resuspended in a known volume of GS medium. Aliquots $(100, \mu 1)$ of this stock cell suspension were diluted with Isoton II (Curtin Matheson Sci. Co.) for cell counting with an electronic particle counter (Coulter Counter, Model Z). After counting, the stock cell suspension was diluted with GS medium to a concentration of 20 million cells per ml. Aliquots for control and dialkyltintreated samples were taken from the same stock cell suspension. Each stock cell suspension contained cells pooled from thymus glands of several animals. At least $90-95 \%$ of the cells were viable based on their ability to exclude trypan blue; the total number of cells and the percentage of cells excluding the dye did not significantly change during a $4-\mathrm{hr}$ incubation interval at $37^{\circ} \mathrm{C}$ with DETD concentrations as high as $100 \mu \mathrm{M}$.

The buffered GS medium was used as the solvent system for the various agents (DETD, AIB, thymidine, uridine, lipoic acid, and insulin) which were added to the cell suspensions.
Amino acid transport. $\left[\alpha{ }^{-14} \mathrm{C}\right]$ Aminoisobutyric acid is used for measuring amino acid transport because it is not metabolized. Transport of $\left[{ }^{14} \mathrm{C}\right] \mathrm{AIB}(56.5 \mathrm{mCl} /$ mol, ICN Chemical and Radioisotope Division, Irvine, Ca.) was determined by the technique of Goldfine $e t$ al. (1972) with minor modifications. Suspended thymocytes (20 million per $\mathrm{ml}$ ) were incubated at $37^{\circ} \mathrm{C}$ with and without DETD ${ }^{3}$ (Ventron Alpha Products). [ $\left.{ }^{+4} \mathrm{C}\right] \mathrm{AIB}$ $(1.62 \mu \mathrm{Ci} / \mu \mathrm{mol})$ was then added and the incubation was continued. Final incubation volume was $1 \mathrm{ml}$ and the final AIB concentration was usually $15 \mu \mathrm{M}$. AIB influx was allowed to proceed for $20 \mathrm{~min}$ while incubating at $37^{\circ} \mathrm{C}$ in a Dubnoff metabolic shaker. To terminate uptake of the labeled amino acid and remove extracellular $\left[{ }^{14} \mathrm{C}\right] \mathrm{AIB}$, the samples were placed in an ice bath followed by the addition of $4 \mathrm{ml}$ of iced GS medium. After centrifugation at $1000 \mathrm{~g}$ for $5 \mathrm{~min}\left(4^{\circ} \mathrm{C}\right)$. the supernatants were dicarded and the pellets resuspended in $4 \mathrm{ml}$ of iced GS medium. The supernatants were again discarded after centrifugation. One milliliter of $10 \% \mathrm{HClO}_{4}$ was added to each washed cell pellet in order to release labeled amino acid accumulated in the cells. The mixtures were allowed to stand for approximately $4 \mathrm{hr}$ prior to agitating and centrifuging at $1500 \mathrm{~g}$ for $10 \mathrm{~min}$. Aliquots $(0.5 \mathrm{ml})$ of the supernatants were dispersed into $15 \mathrm{ml}$ Brays solution for liquid scintillation counting. AIB influx was calculated from the accumulation of cellular radioactivity, specific activity of $\left[{ }^{14} \mathrm{C}\right] \mathrm{AlB}$ in the incubation medium, and cell concentration. Control and dialkyltin-treated samples were run in triplicate.

Nucleoside incorporation by suspended rat thymocytes. Suspended rat thymocytes ( 20 million per $\mathrm{ml}$ ) were incubated with and without DETD in Dubnof metabolic shaker at $37^{\circ} \mathrm{C}$. Following the incubation with dialkyltin, [5-methyl $\left.{ }^{3} \mathrm{H}\right]$ thymidine $(51.4 \mathrm{Ci} / \mathrm{mmol}$, New England Nuclear) or $\left[5^{3} \mathrm{H}\right]$ uridine $(25.9 \mathrm{Ci} / \mathrm{mmol}$, New England Nuclear) was added $(0.333 \mu \mathrm{Ci} / \mathrm{ml}$ final concentration) to both control and treated samples in a $50 \mu \mathrm{l}$ volume of GS medium using a Hamilton syringe with repeating dispenser. The final incubation volume was $1 \mathrm{ml}$ per sample. Incorporation of the labeled nucleosides was allowed to proceed for $60 \mathrm{~min}$ while incubating in a Dubnoff metabolic shaker at $37^{\circ} \mathrm{C}$. Four milliliters of iced GS medium was then added per sample, followed by centrifugation at $1500 \mathrm{~g}$ for $5 \min \left(4^{\circ} \mathrm{C}\right)$. The supernatants were discarded and the washing procedure was repeated one time.

The amount of labeled nucleoside incorporated into nucleic acids was determined by the following procedure. Iced $10 \%$ TCA $(4 \mathrm{ml})$ was added to the washed cell pellets. The samples were then agitated vigorously and centrifuged at $4000 \mathrm{~g}\left(4^{\circ} \mathrm{C}\right)$ for $5 \mathrm{~min}$. The super-

\footnotetext{
${ }^{3}$ Purity was evaluated by thin layer chromatography: triethyltin contamination was estimated to be less than $1 \%$.
} 
natants were then discarded and the samples washed one additional time with $4 \mathrm{ml}$ of $10 \%$ TCA. One milliliter of $5 \%$ TCA was then added to each pellet prior to heating the samples at $80-85^{\circ} \mathrm{C}$ for $15 \mathrm{~min}$. Immediately after removing from the hot bath, the samples were centrifuged at $4000 \mathrm{~g}$ for $5 \mathrm{~min}\left(23^{\circ} \mathrm{C}\right)$. Aliquots $(0.5 \mathrm{ml})$ of the supernatants were then added to $15 \mathrm{ml}$ of Brays solution for liquid scintillation counting.

Statistics. Dunnett's test or Student's $t$ test were used to determine the statistical significance of differences between means; $p<0.05$ was regarded as significant.

\section{RESULTS}

In Vitro Effects of DETD on Amino Acid Transport in Suspended Rat Thymocytes

DETD inhibited the influx of AIB in suspended rat thymocytes in vitro (Fig. 1). Progressively greater inhibition of AIB influx occurred as DETD concentrations increased from 10 to $150 \mu \mathrm{M}$.

The time course of the inhibition of AIB influx by DETD $(25 \mu \mathrm{M})$ is indicated in Fig. 2. DETD was added to suspensions of thymocytes at $37^{\circ} \mathrm{C}$. AIB was then added at various times after the addition of DETD, and influx was determined after $20 \mathrm{~min}$. A pronounced inhibition of AIB influx occurred after only 5 min of preincubation with DETD. Inhibition of AIB influx was nearly maximal after

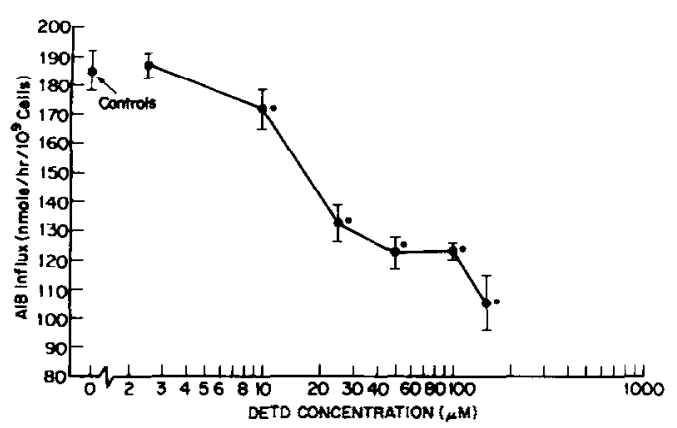

FIG. 1. Effect of diethyltindichloride (DETD) on $\alpha$-aminoisobutyrate (AIB) influx by suspended rat thymocytes. Each point represents the mean $\pm \mathrm{SD}_{\bar{x}}$ of triplicate samples. The samples were incubated with DETD for $\mathbf{3 0 ~ m i n ~ p r i o r ~ t o ~ a ~} \mathbf{2 0 ~ m i n ~ i n c u b a t i o n ~ i n ~ t h e ~ p r e s e n c e ~}$ of AIB. Asterisk indicates statistical difference from control sample mean using Dunnett's test $(p<0.05)$.

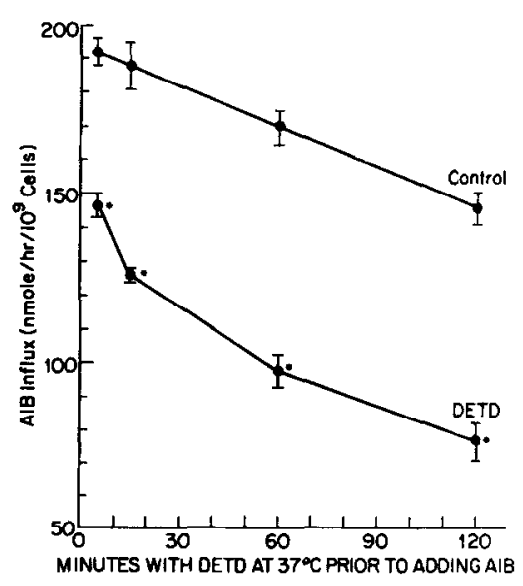

FIG. 2. Effect of incubation time with diethyltindichloride (DETD) on $\alpha$-aminoisobutyrate (AIB) influx in suspended rat thymocytes. Samples were incubated with and without DETD for various time intervals prior to a $20 \mathrm{~min}$ incubation in the presence of AIB. Each point represents the mean $\pm \mathrm{SD}_{\bar{x}}$ of triplicate samples. Asterisk indicates statistical difference from control sample mean using Student's $t$ test $(p<0.05)$.

only $15 \mathrm{~min}$ of preincubation with the dialkyltin. The short preincubation interval required to inhibit AIB transport suggests an action at the cell membrane since longer incubation intervals might be expected for intracellular effects.

Insulin acts as a mitogen in many cell culture systems, and it is known to stimulate the uptake of AIB in suspended rat thymocytes. Therefore the effect of the dialkyltin on insulin-mediated AIB influx was evaluated. Suspended thymocytes were incubated with insulin $(3 \mu \mathrm{M})$ and various concentrations of DETD for $2 \mathrm{hr}$ at $37^{\circ} \mathrm{C}$. AIB was then added and uptake was allowed for 20 min. There was a marked decrease in AIB influx in insulin-treated cells due to concomitant DETD exposure compared to noninsulin-treated cells also exposed to DETD (Fig. 3). DETD concentrations from $2.5 \mu \mathrm{M}$ did not significantly reduce AIB influx below control levels. However these same DETD concentrations had a very pronounced effect on insulin-stimulated AIB influx; $10 \mu \mathrm{M}$ DETD reduced the AIB influx in insulintreated samples almost to control levels. The 


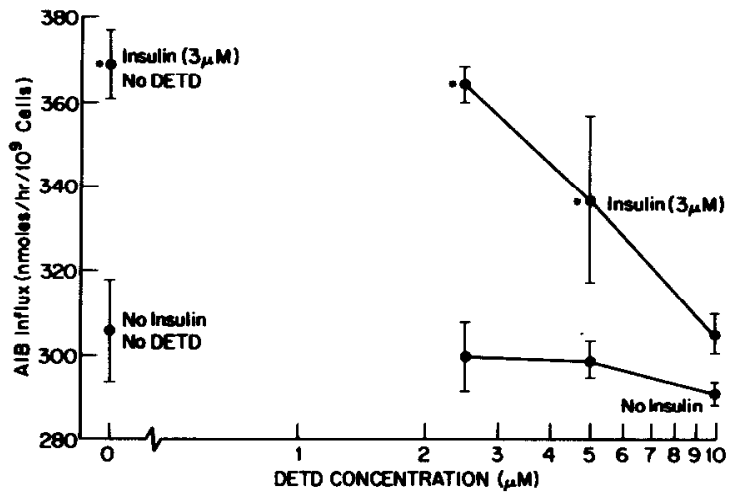

FIG. 3. Effect of diethyltindichloride (DETD) on insulin-stimulated $\alpha$-aminoisobutyrate (AIB) influx in suspended rat thymocytes. Samples were incubated with and without insulin and DETD for $2 \mathrm{hr}$ prior to a 20 min incubation in the presence of AIB. Each point represents the mean $\pm \mathrm{SD}_{\bar{x}}$ of triplicate samples. Asterisk indicates statistical difference from control sample mean using Dunnett's test $(p<0.05)$.

inhibition of insulin-mediated AIB influx may be due to a dialkyltin action on the cell membrane which alters the insulin receptor.

Dialkyltins are known to have marked affinity for dithiols. 'Therefore, lipoic acid (disulfide and reduced) was evaluated as a possible protective agent against the in vitro inhibitory effects of the dialkyltins on AIB transport (Fig. 4). DETD inhibited AIB influx in suspended rat thymocytes both in the presence and absence of the oxidized form of lipoic acid. However, AIB influx was not inhibited when the reduced form of lipoic acid was present in the incubation medium. The protection provided by the reduced form of lipoic acid probably resulted from binding of the DETD with the vicinal

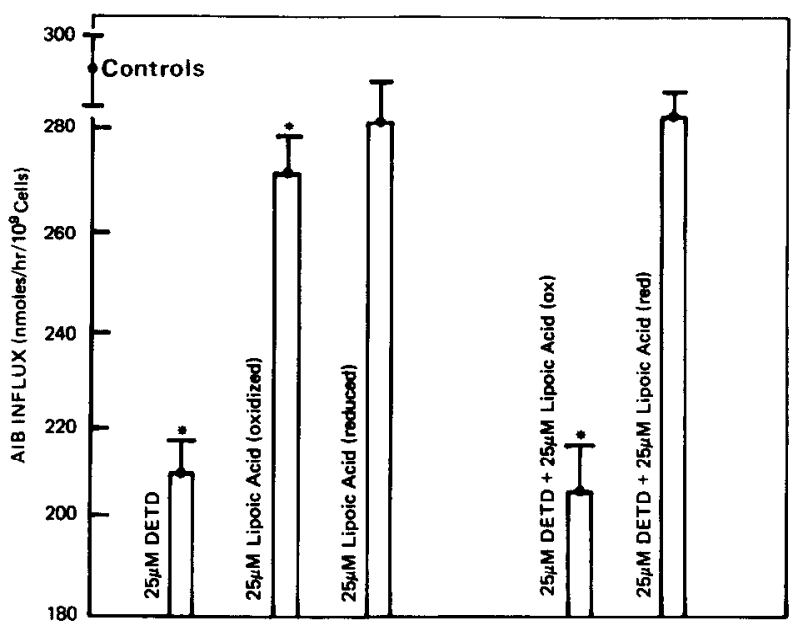

FIG. 4. Effect of diethyltindichloride (DETD) and lipoic acid on $\alpha$-aminoisobutyrate (AIB) influx in suspended rat thymocytes. Samples were incubated with and without DETD and lipoic acid for $15 \mathrm{~min}$ prior to a $20 \mathrm{~min}$ incubation in the presence of $\mathrm{AIB}$. Each point represents the mean $\pm \mathrm{SD}_{\bar{x}}$ of triplicate samples. Asterisk indicates statistical difference from control sample mean using Dunnett's test $(p<0.05)$. 


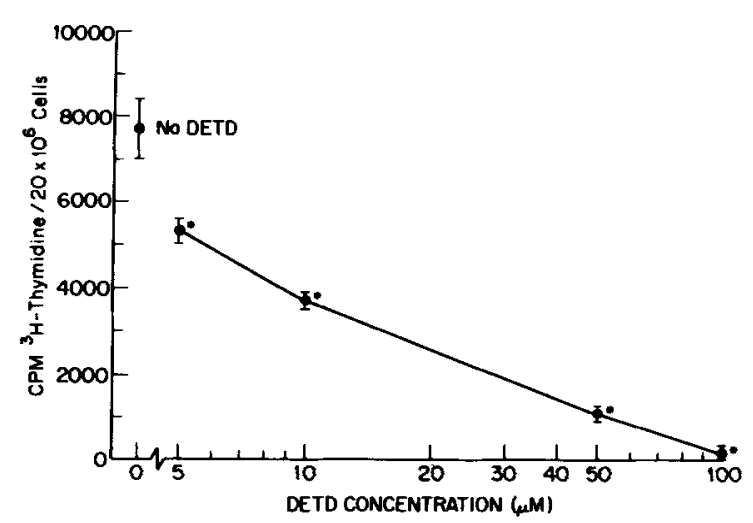

FIG. 5. Effect of diethyltindichloride (DETD) on [5-methyl $\left.{ }^{3} \mathrm{H}\right]$ thymidine incorporation into DNA of suspended rat thymocytes. Samples were incubated with and without DETD for $2 \mathrm{hr}$; labeled thymidine was then added and samples incubated for $1 \mathrm{hr}$. Each point represents the mean $\pm \mathrm{SD}_{\bar{x}}$ of triplicate samples.

sulfhydryl groups of lipoic acid in the incubation medium, in accordance with the reported affinity of dialkyltins for dithiol groups. The results suggest that DETD could inhibit membrane oxidation-reduction systems by combining with critical dithiols, thus preventing their conversion to disulfide linkages in oxidation-reduction reactions.

\section{Effects of DETD on the in Vitro Incorpora- tion of Labeled Nucleosides}

The effects of DETD on the incorporation of labeled thymidine and uridine into nucleic acids were investigated in order to estimate effects on DNA and RNA synthesis. There was a pronounced inhibition of $\left[{ }^{3} \mathrm{H}\right]$ thymidine incorporation into DNA of suspended rat thymocytes incubated with DETD (Fig. 5). The inhibition of labeled thymidine incorporation was evident with DETD concentrations as low as $5 \mu \mathrm{M}$, and the inhibition became progressively greater with increasing dialkyltin concentrations. On the other hand, incorporation of $\left[{ }^{3} \mathrm{H}\right]$ uridine into RNA was markedly stimulated in cells incubated with DETD (Fig. 6), and the stimulation of labeled uridine incorporation became progressively greater with increasing dialkyltin concentrations. The results shown in Figs. 5 and 6 indicate the amounts of labeled nucleoside precursors in nucleic acids, and could reflect alterations in the transport of the labeled nucleoside precursors into the cells rather than alterations of intracellular mechanisms for DNA and RNA synthesis. Additional experiments were therefore conducted to determine the whole cell content of the nucleosides following incubation with $\left[{ }^{3} \mathrm{H}\right]$ thymidine and $\left[{ }^{3} \mathrm{H}\right]$ uridine. Suspended thymocytes were incubated with various concentrations of DETD at $37^{\circ} \mathrm{C}$ for $30 \mathrm{~min}$. Labeled thymidine

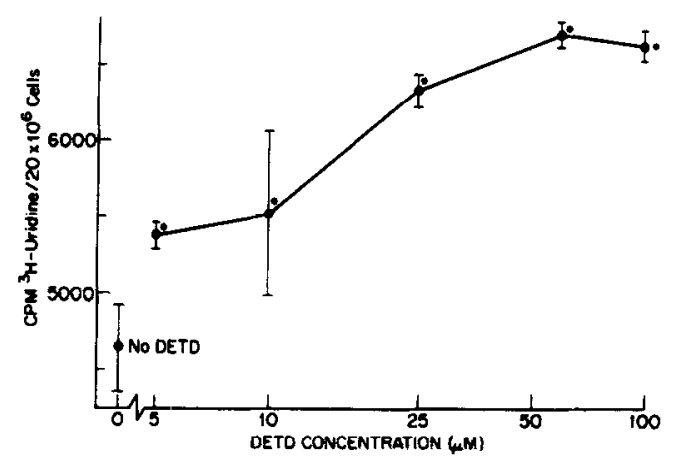

FIG. 6. Effect of diethyltindichloride (DETD) on [5- $\left.{ }^{3} \mathrm{H}\right]$ uridine incorporation into RNA of suspended rat thymocytes. Samples were incubated with and without DETD for $20 \mathrm{~min}$ prior to a $1 \mathrm{hr}$ incubation in the presence of labeled uridine. Each point represents the mean $\pm \mathrm{SD}_{\bar{x}}$ of triplicate samples. 


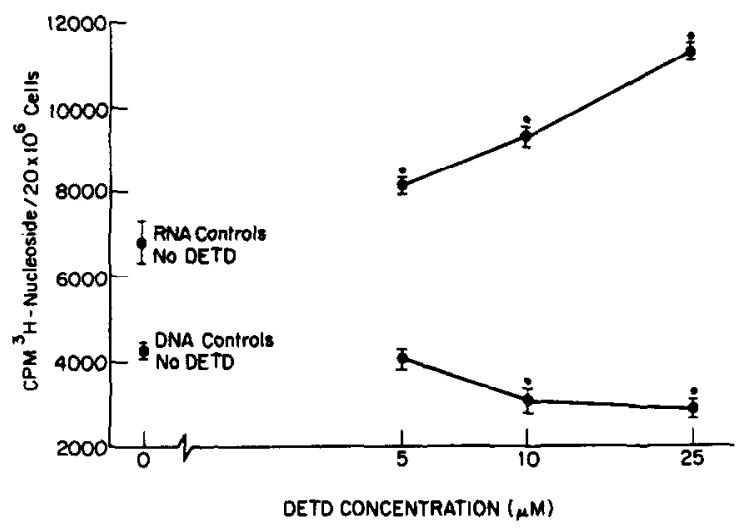

FIG. 7. Effect of diethyltindichloride (DETD) on $\left[5-{ }^{3} \mathrm{H}\right]$ uridine and $\left[5-\right.$ methyl $\left({ }^{3} \mathrm{H}\right]$ thymidine accumulation by suspended rat thymocytes. Samples were incubated with and without DETD for 20 min prior to a $1 \mathrm{hr}$ incubation in the presence of labeled nucleosides. Each point represents the mean $\pm \mathrm{SD}_{\bar{x}}$ of triplicate samples.

or uridine was then added $(0.333 \mu \mathrm{Ci} / \mathrm{ml})$ and incorporation was allowed for $60 \mathrm{~min}$. After washing with iced, buffered GS medium, the washed pellets were dissolved overnight with $1.0 \mathrm{ml}$ of Unisol Tissue Solubilizer. Aliquots of the solubilized pellets were then added to $10 \mathrm{ml}$ Unisol Complement for scintillation counting. A progressive decrease in $\left[{ }^{3} \mathrm{H}\right]$ thymidine content was observed with increasing DETD concentrations while, on the other hand, the cellular $\left[{ }^{3} \mathrm{H}\right]-$ uridine content increased progressively with DETD concentration (Fig. 7). The results indicate that DETD could alter DNA synthesis by inhibiting cell transport of the essential nucleoside precursor for DNA synthesis. Likewise, the dialkyltin could also alter RNA synthesis by increasing cell transport of the essential nucleoside precursor for RNA synthesis.

\section{DISCUSSION}

Diethyltindichloride (DETD) has been shown to markedly inhibit transport of the amino acid $\alpha$-aminoisobutyrate (AIB) in resting as well as in insulin-stimulated thymic cells in vitro. The AIB transport system and the action of insulin on AIB transport in rat thymocytes have been extensively studied (Goldfine et al., 1972; Goldfine and Sherline, 1972; Batzri and Gardner, 1976). The uptake of amino acids into mammalian cells is quite complex and involves numerous separate systems with overlapping specificity; AIB is thought to be transported in thymocytes by a system analogous to the A-(alanine-preferring) system of Ehrlich ascites tumor cells. The A-system has preference for the neutral amino acids, alanine, glycine, and methionine in addition to the nonmetabolizable amino acid AIB. Hence, impairment of the AIB system is probably reflective of a more generalized alteration of neutral amino acid transport. Various agents including cholera toxin, glucocorticoids, and radiation have previously been shown to inhibit AIB transport in rat thymocytes in vitro (Boyle and Gardner, 1974; Baran et al., 1973; Kwock and Wallach, 1974). Kwock et al. (1976) demonstrated the involvement of sulfhydryl groups in the activities of insulin and radiation on AIB transport in rat thymocytes. The very rapid onset of the inhibitory action of DETD on AIB transport suggests an alteration at the cell membrane since longer time intervals would be expected for intracellular mechanisms to be al- 
tered as with glucocorticoids. The protection afforded by lipoic acid demonstrates the affinity of DETD for dithiols; this observation is consistent with the previously reported affinity of dialkyltins for dithiols such as BAL (Aldridge and Cremer, 1955). Thus the inhibitory effects of DETD on AIB transport were thought to be due at least in part to a modification of the reactivity or environment of membrane $\mathrm{SH}$ groups essential for transport of neutral amino acids.

Amino acids and other essential nutrients must be transported into resting cells as well as dividing cells; in resting cells they are required for maintenance, while in dividing cells they are required for growth. According to Bhargava (1975), an increase in the rate of transport of essential nutrients is possibly the earliest response of a resting cell to a mitotic stimulus, and the primary event occurs on the cell surface when a resting cell is triggered into the division cycle by a mitogen such as insulin. Therefore, the inhibitory action of DETD on insulin-mediated AIB transport may reflect an impairment of the ability of thymic cells to divide in response to a mitotic stimulus. Since the thymic cortex normally accounts for $90 \%$ of the thymus weight, and since mitotic activity of the thymic cortical lymphocytes is normally very intense (Metcalf, 1966), an inhibition of mitosis of thymic cortical lymphocytes could account for the pronounced effects of dialkyltins on the thymus gland of rodents in vivo. However, cell culture studies (growth curves) would be required in order to conclusively establish this point.

The inhibition of labeled thymidine incorporation into DNA of suspended thymocytes further suggests that DETD alters the ability of thymic cells to divide. The inhibition of labeled thymidine incorporation into DNA may have been secondary to an inhibitory effect on the transport system for this nucleoside precursor. Incorporation of labeled uridine into RNA of suspended thymocyte was markedly stimulated, possibly via stim- ulation of transport. The significance of this observation is unknown, and further studies would be required to resolve the mechanism by which DETD exerts the differential effects on labeled thymidine and uridine incorporation.

\section{REFERENCES}

Aldridge, W. N., And Cremer, J. E. (1955). The biochemistry of organotin compounds. Biochemistry 61, 406-418.

Baran, D. T., Peck, W. A., Frengleys, P. A., And Lichtman, M. A. (1973). Cortisol-induced inhibition of amino acid transport in thymic lymphocytes: Kinetic parameters; relation to ATP levels and protein synthesis; and specificity. Biochim. Biophys. Acta 307, 627-639.

BAtzri, S., ANd Gardner, J. D. (1976). Amino acid transport in isolated rat thymocytes. J. Biol. Chem. 251(19), 6030-6035.

Bhargava, P. M. (1975). Possible relationship between regulation of uptake of essential nutrients and regulation of cell division in higher organisms. In Regulation of Growth and Differentiated Function in Eucaryote Cells. (G. P. Talwar, cd.), pp. 79-91. Raven Press, New York.

Boyle, J. M., ANd Gardner, J. D. (1974). Sequence of events mediating the effect of cholera toxin on rat thymocytes. J. Clin. Invest. 53(4), 1149-1158.

Goldfine, I. D., Gardner, J. D., And Neville, D. M. . JR. (1972). Insulin action in isolated rat thymocytes. I. Binding of ${ }^{125}$ I-insulin and stimulation of $\alpha$-aminoisobutyric acid transport. J. Biol. Chem. 247(21), 6919-6926.

Goldfine, I. D., ANd Sherline, P. (1972). Insulin action in isolated rat thymocytes, II. Independence of insulin and cyclic adenosine monophosphate. $J$. Biol. Chem. 247(21), 6927-6931.

Goldfine, I. D., Simons, C. G., Smith, G. J., AND INGBAR, S. H. (1975). Cycloleucine transport in isolated rat thymocytes: In vitro effects of triiodothyronine and thyroxin. Endocrinology 96(4), 1030-1037.

Kwock, L., AND Wallach, D. F. H. (1974). The effect of ionizing radiation on amino acid transport systems in thymocytes. Biochim. Biophys. Acta 352, $135-145$

Kwock, L., Wallach, D. F. H., and Hefter, K. (1976). Involvement of sulfhydryl groups in the action of insulin and radiation on thymocyte $\mathrm{Na}^{+}$dependent amino acid transport. Biochim. Biophys. Acta 419, 93-103.

Metcalf, D. (1966). The thymus. Recent Results in Cancer Research, Vol. 5. Springer-Verlag, New York. 
Seinen, W., AND Willems, M. I. (1976). Toxicity of organotin compounds. I. Atrophy of thymus and thymus-dependent lymphoid tissue in rats fed din-octyl-tindichloride. Toxicol. Appl. Pharmacol. 35, 63-75.

Seinen, W., Vos, J. G., Krieken, R. V., Penninks, A., Brands, R., AND HooykaAs, H. (1977a). Toxicity of organotin compounds. III. Suppression of thymus-dependent immunity in rats by di- $n$-butyl- tindichloride and di- $n$-octyltindichloride. Toxicol. Appl. Pharmacol. 42, 213-224.

Seinen, W., Vos, J. G., Spanje, I. V., Snoek, M., Brands, R., and HooykaAs, H. (1977b). Toxicity of organotin compounds. II. Comparative in vivo and in vitro studies with various organotin and organolead compounds in different animal species with special emphasis on lymphocyte eytotoxicity. Toxicol. Appl. Pharmacol. 42, 197-212. 